\title{
Regression of macular edema secondary to branch retinal vein occlusion during anti-TNF- $\alpha$ therapy for rheumatoid arthritis
}

This article was published in the following Dove Press journal:

Clinical Ophthalmology

19 June 2010

Number of times this article has been viewed

\author{
Shu Kachi \\ Kenshin Kobayashi \\ Hiroaki Ushida \\ Yasuki Ito \\ Mineo Kondo \\ HirokoTerasaki \\ Department of Ophthalmology, \\ Nagoya University Graduate School \\ of Medicine, Nagoya, Japan
}

Correspondence: Shu Kachi

Department of Ophthalmology, Nagoya University Graduate School of Medicine, 65 Tsuruma-cho, Showa-ku, Nagoya 466-8550, Japan

Tel +8I 527442277

Fax +81527442278

Email kachishu-ngy@umin.ac.jp

\begin{abstract}
A patient with macular edema secondary to a branch retinal vein occlusion (BRVO) was treated with intravenous injections of infliximab, an antitumor necrosis factor (TNF)- $\alpha$ antibody, for her rheumatoid arthritis (RA). Before the injection, the thickness of the right fovea, determined by optical coherent tomography, was $629 \mu \mathrm{m}$ and the best-corrected visual acuity (BCVA) was 20/50. After eight injections of infliximab and 10 months after the first injection, her foveal thickness was decreased to $293 \mu \mathrm{m}$ and the visual acuity improved to $20 / 20$. There was no recurrence of macular edema during the infliximab injections. However, the infliximab injection was stopped because the patient developed pneumonia. Eight months after stopping the infliximab injection, her foveal thickness increased to $494 \mu \mathrm{m}$. To treat the RA, her orthopedists began weekly subcutaneous injections of etanercept, a fusion protein of a section of the TNF receptor and immunoglobulin. Five months later, the foveal thickness had decreased to $260 \mu \mathrm{m}$, and the visual acuity remained at $20 / 25^{+}$. Because TNF- $\alpha$ is known to break down the blood-retinal barrier, the improvements in our case suggest that TNF- $\alpha$ plays a role in the pathogenesis of macular edema in some patients with BRVO.
\end{abstract}

Keywords: branch retinal vein occlusion, macular edema, tissue necrosis factor-alpha, rheumatoid arthritis, infliximab, etanercept, foveal thickness

\section{Introduction}

Macular edema is one of the most common complications in eyes with branch retinal vein occlusion (BRVO) and a major cause of visual deterioration. ${ }^{1}$ In addition to macular grid laser photocoagulation, ${ }^{2}$ intravitreal injections of steroids, ${ }^{3}$ vitrectomy, ${ }^{4}$ and intravitreal injection of off-label bevacizumab, ${ }^{5}$ a monoclonal antibody against human vascular endothelial growth factor (VEGF), have been used to treat macular edema.

Tumor necrosis factor (TNF)- $\alpha$ is known to play a major role in inflammation, and is used to treat rheumatoid arthritis (RA). Infliximab, a humanized monoclonal anti-TNF- $\alpha$ antibody, and etanercept, a dimeric fusion protein consisting of the extracellular domain of TNF receptor II and the Fc region of human immunoglobulin, are approved and used clinically to treat patients with RA. ${ }^{6,7}$ TNF- $\alpha$ is known to break down the blood-retinal barrier, ${ }^{8}$ and neutrophils activated by TNF- $\alpha$ release elastase which causes damage to endothelial cells and an increase in microvascular permeability. There are reports that anti-TNF- $\alpha$ is effective in treating macular edema associated with uveitis ${ }^{9}$ and diabetic retinopathy. ${ }^{10}$

We report a case of macular edema secondary to BRVO in which the degree of macular edema decreased during anti-TNF- $\alpha$ treatment for RA, increased when the 
anti-TNF- $\alpha$ treatment was stopped, then decreased again when the anti-TNF- $\alpha$ treatment was restarted.

\section{Case report}

A 59-year-old woman noticed a decrease in the vision of her right eye in early June 2006, and because she was being treated for RA in the Department of Orthopedics at Nagoya University Hospital, she was referred to the Department of Ophthalmology at the same institution on 30 June 2006. At that time, she was being treated with prednisolone $5 \mathrm{mg}$ /day, diclofenac sodium $75 \mathrm{mg} /$ day, salazosulfapyridine $1000 \mathrm{mg}$ /day, and methotrexate $8 \mathrm{mg} /$ week for her RA. Her best-corrected visual acuity (BCVA) was 20/40 OD, and macular edema due to a BRVO was detected. Her foveal thickness determined by optical coherent tomography (OCT; OCT2000 or Stratus, Carl Zeiss Meditec, Oberkochen, Germany) was $679 \mu \mathrm{m}$.

After obtaining approval from The Nagoya University Hospital internal ethics review board and her informed consent, she was treated with intravitreal bevacizumab (IVB) beginning on 07 August 2006. She was injected with IVB three times, and the foveal thickness after each injection was 298, 317, and $237 \mu \mathrm{m}$, and the BCVA was 20/40, 20/40, and $20 / 33$, respectively. Although bevacizumab was effective in decreasing the macular edema, the decrease was transient. After the third injection, the patient refused further injections. Thus, the final bevacizumab injection was on November 14, 2006, and she was followed up without any ophthalmologic treatment.

On 28 December 2006, the foveal thickness determined by OCT was $629 \mu \mathrm{m}$, and the BCVA was 20/50 (Figures $1 \mathrm{~A}$ and $1 \mathrm{~B})$. Because the RA was not well controlled with the oral treatment listed above, intravenous injections of infliximab
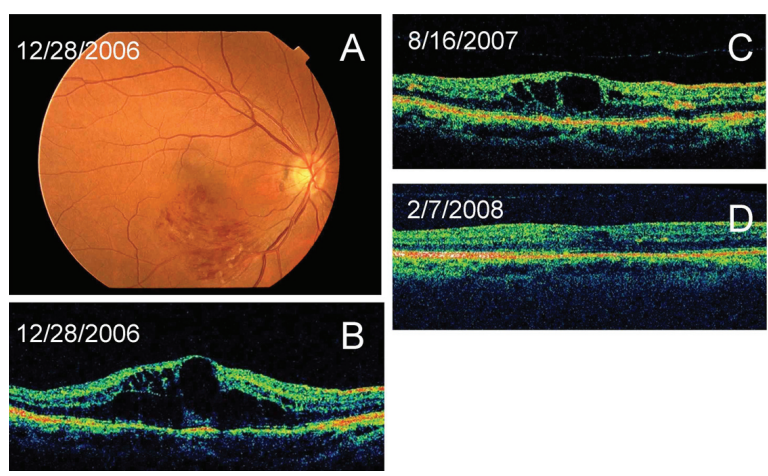

Figure I Fundus photographs and OCT images of a patient with macular edema associated with a BRVO. The patient was treated with infliximab. A) Fundus photograph of the right eye before the infliximab injections. B) OCT image of the right eye before the infliximab injections. C) OCT image of the right eye 10 months after the first infliximab injection. D) OCT image of the right eye 19 months after the first infliximab injection. E) Changes of foveal thickness and visual acuity during the infliximab treatment. Abbreviations: BRVO, branch retinal vein occlusion; OCT, optical coherence tomography.

$150 \mathrm{mg}$ were started by the orthopedists on March 29, 2007. After five infliximab injections, the foveal thickness decreased to $465 \mu \mathrm{m}$. After the sixth injection of infliximab $150 \mathrm{mg}$, the amount of infliximab was increased to $200 \mathrm{mg}$, and after the second injection of $200 \mathrm{mg}$ infliximab on February 7, 2008, the foveal thickness in her right eye decreased to $314 \mu \mathrm{m}$, and her visual acuity was 20/25 (Figure 1C). There was no recurrence of macular edema during the infliximab injections, and her right foveal thickness was $309 \mu \mathrm{m}$ and her BCVA was 20/20 on September 26, 2008 (Figures 1D and 1E).

The infliximab injections were stopped on December 12, 2008 because she developed pneumonia and had joint surgery. She did not return to our department until May 29, 2009, more than five months after her last infliximab injection. We found that the macular edema had recurred, and the foveal thickness was $494 \mu \mathrm{m}$ (Figures 2A and 2B). On June 5, 2009, her orthopedists started a $25 \mathrm{mg} /$ week subcutaneous injection of etanercept to treat the RA. On July 3, 2009, about one month after the start of the etanercept injections, the foveal thickness had decreased to $369 \mu \mathrm{m}$ (Figure 2C) and, on October 23, 2009, about five months after the start of the etanercept injections, the foveal thickness was $260 \mu \mathrm{m}$ (Figures 2D and $2 \mathrm{E})$. Her BCVA in the right eye was $20 / 25$ or better throughout the period of etanercept treatment.

\section{Discussion}

We report the findings in a patient whose macular edema regressed after infliximab injections, as a secondary effect to her treatment for RA, then recurred after stopping the injections. The macular edema regressed again following etanercept injections. The infliximab injections were started nine months after the onset of the BRVO, and etanercept injection was started three years after the onset. These findings

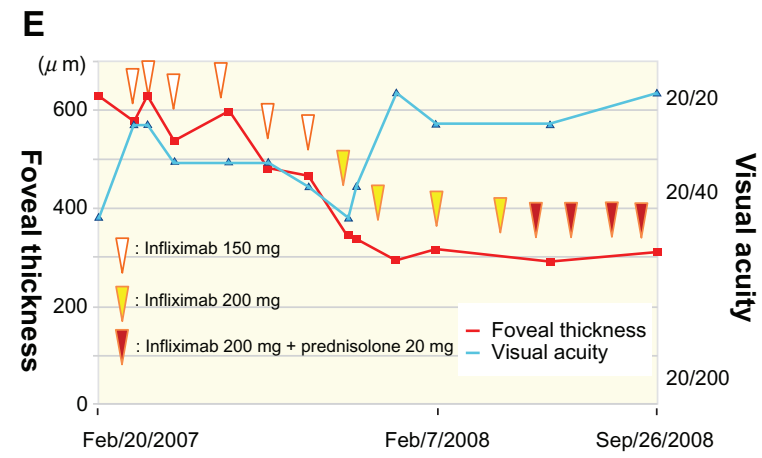



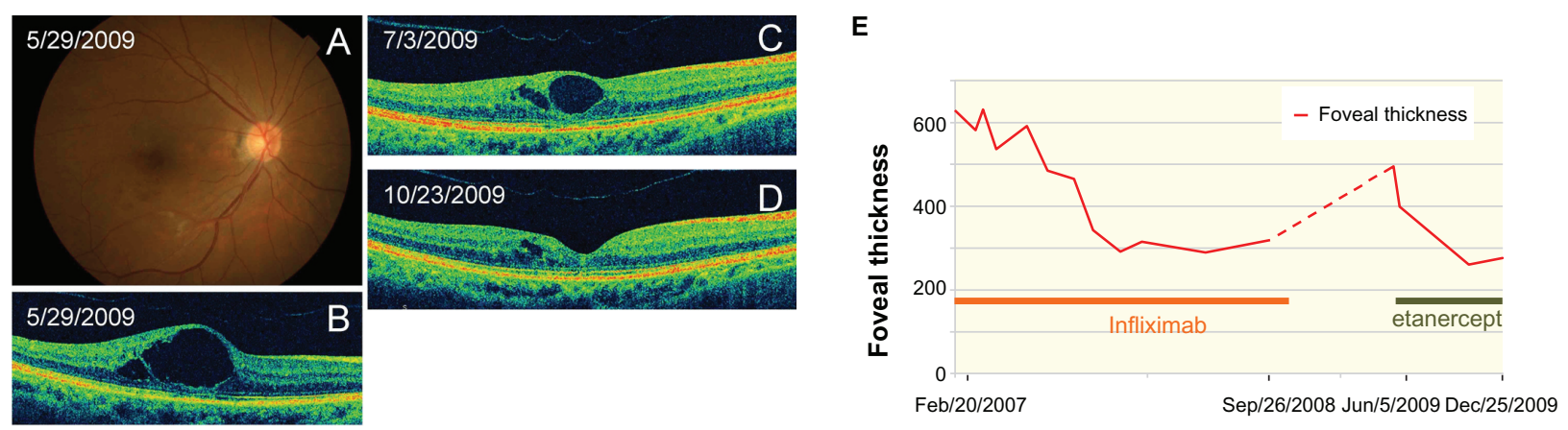

Figure 2 Fundus photographs and OCT images of an eye with macular edema that was reduced by intravitreal etanercept injections. A) Fundus photograph of the right eye before the etanercept injection. B) OCT image before the etanercept injection. C) OCT image of the right eye one month after the first etanercept injection. D) OCT image four months after the first etanercept injection. E) Changes of foveal thickness during infliximab and etanercept treatments.

Abbreviation: OCT, optical coherence tomography.

strongly suggest that these anti-TNF- $\alpha$ drugs were effective in reducing the degree of macular edema. However, the foveal thickness decreased gradually for more than six months after starting the infliximab, and more than three months after starting etanercept. In addition, when the infliximab was stopped for eight months, the macular edema recurred. These results suggest that repeated anti-TNF- $\alpha$ injections are needed to obtain the maximum effect, and the injections need to be continued to remain effective. Because the reduction of foveal thickness was transient, similar to anti-VEGF treatment, it is suggested that there could have been a systemic process occurring that may have influenced this localized inflammatory process.

Both VEGF and TNF- $\alpha$ are known to break down the blood-retinal barrier, ${ }^{8}$ and there are some reports that anti-TNF- $\alpha$ treatment is effective against macular edema associated with uveitis. ${ }^{9}$ Additionally, Sfikakis et al reported that anti-TNF- $\alpha$ treatment was effective in four of six eyes with diabetic macular edema, but not for two eyes with an epiretinal membrane. ${ }^{10}$ There is still no evidence that the ocular level of TNF- $\alpha$ is increased in eyes with macular edema secondary to BRVO. ${ }^{11}$ However, because injections of steroids are effective in treating the macular edema secondary to $\mathrm{BRVO},{ }^{3}$ low-grade inflammation seems to play a role in the pathogenesis of chronic macular edema secondary to BRVO. Our findings suggest that TNF- $\alpha$ may also contribute to the macular edema.

Macrophages are found on the inner limiting membrane of eyes with macular edema, ${ }^{12}$ and TNF- $\alpha$ is known to activate macrophages and increase VEGF expression. ${ }^{13}$ In addition, there has been a report of a significant reduction of macrophages and VEGF in RA patients after anti-TNF- $\alpha$ treatment. ${ }^{14}$ These reports suggest that anti-TNF- $\alpha$ therapy resolve the macular edema not by decreasing vascular permeability directly, but by decreasing the expression of VEGF and/or other proteins related to inflammation.

\section{Conclusion}

From the clinical course of our patient, we conclude that TNF- $\alpha$ plays a role in the pathogenesis of her chronic macular edema secondary to BRVO. These findings suggest that antiTNF- $\alpha$ should be considered for the treatment of macular edema secondary to BRVO.

\section{Acknowledgments}

The authors thank Professor Duco Hamasaki of Bascom Palmer Eye Institute for discussions and editing the final version of the manuscript. Grant support was received from Grant-in Aid 19791262 (SK), 19500416 (YI), 18591913 (MK), and 18390466 (HT) at the Ministry of Education, Science, Sports and Culture, Japan.

\section{Disclosure}

The authors have no proprietary interest in this research.

\section{References}

1. Rehak J, Rehak M. Branch retinal vein occlusion: Pathogenesis, visual prognosis, and treatment modalities. Curr Eye Res. 2008;33:111-131.

2. The Branch Vein Occlusion Study Group. Argon laser photocoagulation for macular edema in branch vein occlusion. The Branch Vein Occlusion Study Group. Am J Ophthalmol. 1984;98:271-282.

3. Avitabile T, Longo A, Reibaldi A. Intravitreal triamcinolone compared with macular laser grid photocoagulation for the treatment of cystoid macular edema. Am J Ophthalmol. 2005;140:695-702.

4. Osterloh MD, Charles S. Surgical decompression of branch retinal vein occlusions. Arch Ophthalmol. 1988;106:1469-1471.

5. Rabena MD, Pieramici DJ, Castellarin AA, Nasir MA, Avery RL. Intravitreal bevacizumab (Avastin) in the treatment of macular edema secondary to branch retinal vein occlusion. Retina. 2007;27:419-425.

6. Elliott MJ, Maini RN, Feldmann M, et al. Randomised double-blind comparison of chimeric monoclonal antibody to tumour necrosis factor alpha (cA2) versus placebo in rheumatoid arthritis. Lancet. 1994;344:1105-1110. 
7. Murray KM, Dahl SL. Recombinant human tumor necrosis factor receptor (p75) Fc fusion protein (TNFR:Fc) in rheumatoid arthritis. Ann Pharmacother. 1997;31:1335-1338.

8. Luna JD, Chan CC, Derevjanik NL, et al. Blood-retinal barrier (BRB) breakdown in experimental autoimmune uveoretinitis: Comparison with vascular endothelial growth factor, tumor necrosis factor alpha, and interleukin-1beta-mediated breakdown. J Neurosci Res. 1997;49: 268-280.

9. Markomichelakis NN, Theodossiadis PG, Pantelia E, Papaefthimiou S, Theodossiadis GP, Sfikakis PP. Infliximab for chronic cystoid macular edema associated with uveitis. Am J Ophthalmol. 2004;138:648-650.

10. Sfikakis PP, Markomichelakis N, Theodossiadis GP, Grigoropoulos V, Katsilambros N, Theodossiadis PG. Regression of sight-threatening macular edema in Type 2 diabetes following treatment with the antitumor necrosis factor monoclonal antibody infliximab. Diabetes Care. $2005 ; 28: 445-447$.
11. Campochiaro PA, Choy DF, Do DV, et al. Monitoring ocular drug therapy by analysis of aqueous samples. Ophthalmology. 2009; Nov;116:2158-2164.

12. Gandorfer A, Rohleder M, Grosselfinger S, Haritoglou C, Ulbig M, Kampik A. Epiretinal pathology of diffuse diabetic macular edema associated with vitreomacular traction. Am J Ophthalmol. 2005;139: 638-652.

13. Perez-Ruiz M, Ros J, Morales-Ruiz M, et al. Vascular endothelial growth factor production in peritoneal macrophages of cirrhotic patients: Regulation by cytokines and bacterial lipopolysaccharide. Hepatology. 1999;29:1057-1063.

14. Canete JD, Pablos JL, Sanmarti R, et al. Antiangiogenic effects of anti-tumor necrosis factor alpha therapy with infliximab in psoriatic arthritis. Arthritis Rheum. 2004;50:1636-1641.
Clinical Ophthalmology

\section{Publish your work in this journal}

Clinical Ophthalmology is an international, peer-reviewed journal covering all subspecialties within ophthalmology. Key topics include: Optometry; Visual science; Pharmacology and drug therapy in eye diseases; Basic Sciences; Primary and Secondary eye care; Patient Safety and Quality of Care Improvements. This journal is indexed on

\section{Dovepress}

PubMed Central and CAS, and is the official journal of The Society of Clinical Ophthalmology (SCO). The manuscript management system is completely online and includes a very quick and fair peer-review system, which is all easy to use. Visit http://www.dovepress.com/ testimonials.php to read real quotes from published authors. 